ARTICLE

\title{
Non-covalent synthesis of supermicelles with complex architectures using spatially confined hydrogen-bonding interactions
}

Xiaoyu Li ${ }^{1, \star, \dagger}$, Yang Gao ${ }^{1, \star}$, Charlotte E. Boott ${ }^{1}$, Mitchell A. Winnik ${ }^{2}$ \& lan Manners ${ }^{1}$

Nature uses orthogonal interactions over different length scales to construct structures with hierarchical levels of order and provides an important source of inspiration for the creation of synthetic functional materials. Here, we report the programmed assembly of monodisperse cylindrical block comicelle building blocks with crystalline cores to create supermicelles using spatially confined hydrogen-bonding interactions. We also demonstrate that it is possible to further program the self-assembly of these synthetic building blocks into structures of increased complexity by combining hydrogen-bonding interactions with segment solvophobicity. The overall approach offers an efficient, non-covalent synthesis method for the solution-phase fabrication of a range of complex and potentially functional supermicelle architectures in which the crystallization, hydrogen-bonding and solvophobic interactions are combined in an orthogonal manner.

\footnotetext{
${ }^{1}$ School of Chemistry, University of Bristol, Bristol BS8 1TS, UK. ${ }^{2}$ Department of Chemistry, University of Toronto, Toronto, Ontario M5S 3H6, Canada. * These authors contributed equally to this work. † Present address: Department of Polymer Materials, School of Material Science and Technology, Beijing Institute of Technology, Beijing 100081, China. Correspondence and requests for materials should be addressed to I.M. (email: ian.manners@bristol.ac.uk).
} 
$\mathrm{T}$ he intricate hierarchical structures achieved by nature ${ }^{1}$ using orthogonal interactions on different length scales have inspired the pursuit of artificial materials with complexity and functionality using analogous synthetic concepts $^{2,3}$. Recent breakthroughs in colloidal particle synthesis have enabled their use as building blocks for higher-level assembly ${ }^{4}$. In particular, block copolymers provide a diverse array of soft-matter nanoparticles of varied shape and size $e^{5-10}$, and intricately designed structures such as Janus ${ }^{11-15}$ and patchy particles ${ }^{16-19}$. Several reports have described the assembly of these nanoparticles through electrostatic ${ }^{20}$ or solvophobic interactions ${ }^{11-19}$ into discrete multicomponent composite supermicelles $^{11,12}$ or extended superstructures ${ }^{13-19}$.

Hydrogen-bonding (H-bonding) interactions, which play pivotal roles in the spontaneous organization of building blocks into hierarchical structures in natural systems, have been extensively used to assemble artificial structural units, as illustrated by work on small molecules ${ }^{21-25}$, DNA origami ${ }^{26-28}$, polymer/small molecule pairs $29-31$, polymer/polymer pairs $^{32}$ and polymer/inorganic particles ${ }^{33}$. However, the creation of nanoscale architectures with similar levels of precision to nature by low-cost solution-phase processing remains a key challenge.

Here, we describe the use of cylindrical block comicelles with crystalline cores as building blocks to create complex hierarchical supermicelle structures via $\mathrm{H}$-bonding interactions. Specifically, we demonstrate that fine control of the length and position of $\mathrm{H}$-bonding donor and acceptor segments, made possible by the living crystallization-driven block copolymer self-assembly method, allows the interactions to be confined and the subsequent hierarchical organization of the resulting cylindrical block comicelles to be precisely directed.

\section{Results}

The basic polymer components and building blocks. In Fig. 1a, we show the five different polymers that form the block copolymers studied. All of the block copolymers possessed a crystallizable, core-forming poly(ferrocenyldimethylsilane), PFS block together with a corona-forming segment that was either an H-bonding donor block (hydroxyl-functionalized poly(methylvinylsiloxane), $\mathrm{PMVSOH}, \mathrm{H}_{\mathrm{D}}$ ), an H-bonding acceptor block (poly(2-vinylpyridine), $\mathrm{P} 2 \mathrm{VP}, \mathrm{H}_{\mathrm{A}}$ ), a non-interactive block (poly(tert-butyl acrylate), PtBA, N) or a crosslinkable block (poly(methylvinylsiloxane), PMVS, X). For convenience, as the crystalline PFS core was a common feature, all of the micelles are depicted in an abbreviated form that reflects their coronal chemistry (for example, triblock comicelle $\mathrm{M}\left(\mathrm{PFS}_{20}-b\right.$ - $\mathrm{PtBA}_{280}$ )$b-\mathrm{M}\left(\mathrm{PFS}_{32}-b-\mathrm{P}_{2} \mathrm{VP}_{448}\right)-b-\mathrm{M}\left(\mathrm{PFS}_{20}-b-\mathrm{PtBA}_{280}\right)$ is described as having segments of $\mathrm{N}, \mathrm{H}_{\mathrm{A}}$ and $\mathrm{N}$ and is written as $\mathrm{N}-\mathrm{H}_{\mathrm{A}}-\mathrm{N}$ ). Cylindrical block comicelle building blocks such as $\mathrm{N}-\mathrm{H}_{\mathrm{A}}-\mathrm{N}$ were prepared via living crystallization-driven self-assembly $(\mathrm{CDSA})^{33-38}$. In this process (see Fig. 1b (i)), dissolved block copolymer unimers with a crystallizable core-forming block and different corona-forming blocks can be added sequentially to short cylindrical micelles (seeds), which were prepared by sonication. This allowed the formation of monodisperse cylindrical micelles with segmented structures and lengths controlled from $50 \mathrm{~nm}$ to $5 \mu \mathrm{m}$ (detailed characteristics of all seeds and triblock comicelles used in this study are shown in Supplementary Table 1).

Initial studies of hierarchical assembly via $\mathrm{H}$-bonding interactions. The $\mathrm{H}$-bonding interactions between hydroxyl and pyridyl groups in polymers have been exploited extensively ${ }^{29-32,39}$, and our initial studies focused on exploring their potential use in supermicelle formation. We found that the addition of
$\mathrm{H}_{\mathrm{D}}$ homopolymer to block copolymer seeds with an $\mathrm{H}_{\mathrm{A}}$ corona in isopropanol ( $i-\mathrm{PrOH}$, a selective solvent for both PMVSOH and P2VP blocks) led to the formation of an insoluble precipitate (Supplementary Fig. 2k). On the basis of this observation, we investigated the more controlled interactions between the $\mathrm{H}_{\mathrm{D}}$ homopolymer and $\mathrm{N}-\mathrm{H}_{\mathrm{A}}-\mathrm{N}$ triblock comicelles, in which the $\mathrm{H}_{\mathrm{A}}$ polymer chains were confined to the corona of the central segment of the cylindrical building block (Fig. 1b). From transmission electron microscopy (TEM) analysis, addition of $\mathrm{H}_{\mathrm{D}}$ homopolymer to the $i-\mathrm{PrOH}$ solution of the triblock comicelles at a mole ratio of hydroxyl/pyridyl groups of 5:1 led to assembly of the comicelles through parallel aggregation of the central $\mathrm{H}_{\mathrm{A}}$ coronal segments forming 'fish-spine' supermicelles (Fig. 1b (ii),c; Supplementary Fig. 2g). The $\mathrm{H}_{\mathrm{D}}$ homopolymer chains appeared to function as a 'glue' to enable the triblock comicelles to assemble via H-bonding interactions. Although a distribution of very similar structures was formed in each case, substantial control could be imposed by adjusting various parameters. For example, use of either a very low or very high mole ratio of hydroxyl/pyridyl groups led to a significant reduction of the aggregation number (or arm distribution) in each supermicelle (Supplementary Fig. 2a-e). Furthermore, we were also able to tune the steric hindrance arising from the $\mathrm{N}$ segment by using several $\mathrm{N}$ segment-forming block polymers (PFS- $b$-PtBA) with different PtBA coronal block chain lengths. As shown in Supplementary Fig. $2 \mathrm{f}-\mathrm{j}$, with increasing PtBA block length and thus coronal spatial extent, the aggregation number also decreased.

Next, we replaced $H_{D}$ homopolymer with block copolymer seeds bearing an $\mathrm{H}_{\mathrm{D}}$ corona (Fig. $1 \mathrm{~b}$ (iii) and (iv)) and studied how this changed the assembly behaviour. As an initial experiment, we mixed seeds with an $\mathrm{H}_{\mathrm{D}}$ corona $\left(L_{n}=37 \mathrm{~nm}\right)$ and seeds with a corona of $\mathrm{H}_{\mathrm{A}}\left(L_{n}=45 \mathrm{~nm}\right)$ in $i-\mathrm{PrOH}$. Seconds after mixing, a precipitate was observed in the solution (Supplementary Fig. 2l,m), which indicated the formation of large aggregates via uncontrolled $\mathrm{H}$-bonding interactions. We then explored the analogous assembly process for the $\mathrm{H}_{\mathrm{D}}$ seeds with $\mathrm{N}-\mathrm{H}_{\mathrm{A}}-\mathrm{N}$ triblock comicelles. At a ratio of hydroxyl/pyridyl groups of 20:1, TEM analysis revealed the formation of composite block comicelles with the $H_{D}$ seeds attached to the surface of the central $\mathrm{H}_{\mathrm{A}}$ segments. The presence of a small number of free $\mathrm{H}_{\mathrm{D}}$ seeds was also detected (Fig. 1b (iii),d). Interestingly, when the ratio was decreased to 1:2, instead of forming composite block comicelles, large micelle bundles were obtained, in which each $\mathrm{H}_{\mathrm{D}}$ seed was bound to several $\mathrm{N}-\mathrm{H}_{\mathrm{A}}-\mathrm{N}$ triblock comicelles via H-bonding interactions (Fig. 1b (iv),e; Supplementary Fig. 2n). This behaviour contrasts to that observed in the case involving the addition of $\mathrm{H}_{\mathrm{D}}$ homopolymer to $\mathrm{N}-\mathrm{H}_{\mathrm{A}}-\mathrm{N}$ triblock comicelles, which showed no aggregation at the same ratio (Supplementary Fig. 2a). We attribute the more extensive assembly to the larger size of $\mathrm{H}_{\mathrm{D}}$ seeds compared with the homopolymer chains.

Hierarchical assembly of triblock comicelles via H-bonding. The studies described above suggested that the H-bonding interactions between hydroxyl groups on $\mathrm{H}_{\mathrm{D}}$ chains and the pyridyl groups on $\mathrm{H}_{\mathrm{A}}$ chains were sufficiently strong to build hierarchical structures with a higher level of complexity. We therefore investigated how confined H-bonding interactions would direct the assembly process for triblock comicelles. First, we explored a 'condensation polymerization' of $\mathrm{H}_{\mathrm{D}}-\mathrm{N}-\mathrm{H}_{\mathrm{D}}$ and $\mathrm{H}_{\mathrm{A}}-\mathrm{N}-\mathrm{H}_{\mathrm{A}}$ triblock comicelles where the interacting $\mathrm{H}_{\mathrm{D}}$ and $\mathrm{H}_{\mathrm{A}}$ segments were both placed at the termini and were therefore only shielded by $\mathrm{N}$ segments on one side. To distinguish the two kinds of triblock comicelles in the resulting supermicelles, different $\mathrm{N}$ central segment lengths were used $(680$ and $240 \mathrm{~nm}$ 
a

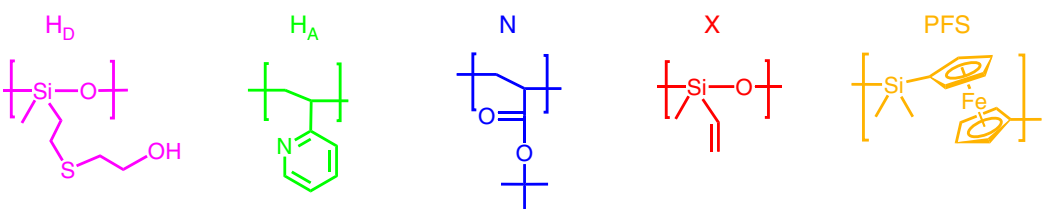

b
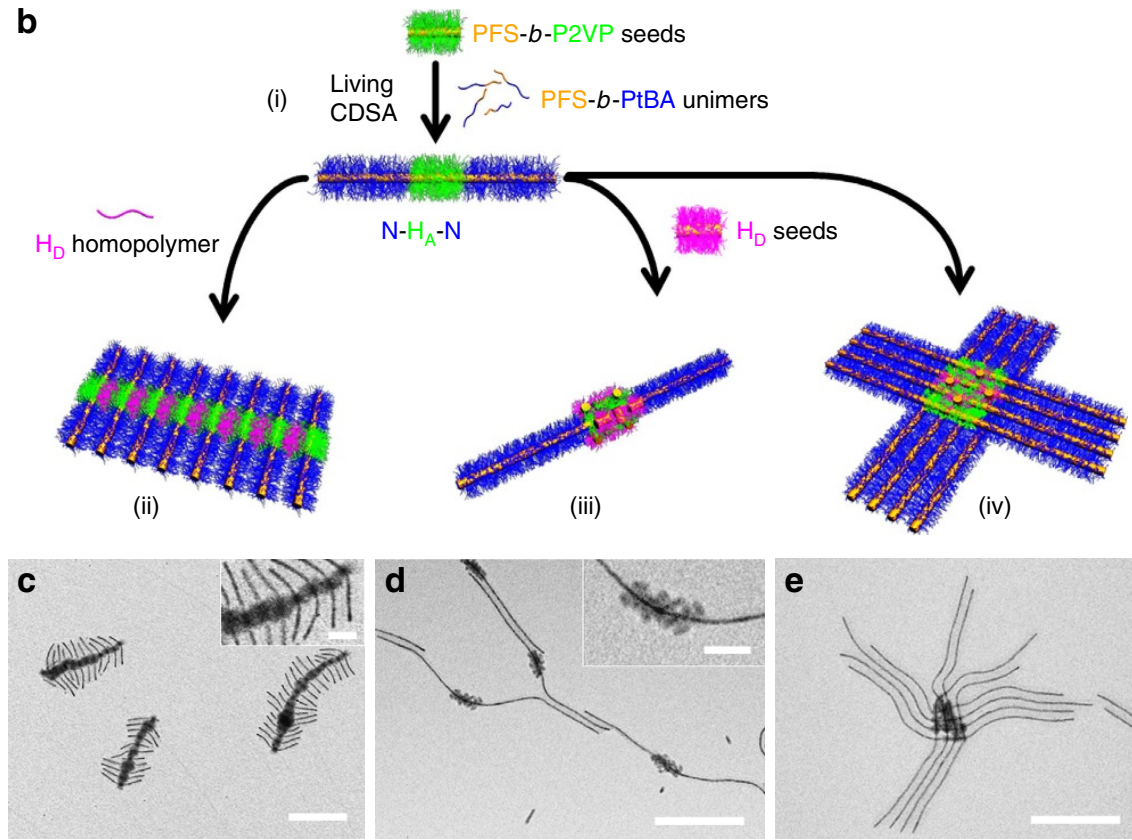

Figure 1 | Initial studies of hierarchical assembly via $\mathbf{H}$-bonding interactions. (a) Chemical structures of PMVSOH $\left(H_{D}\right), P 2 V P\left(H_{A}\right), P t B A(N), P M V S(X)$ and PFS. (b) Schematic of the assembly processes. TEM images after solvent evaporation of supermicelles formed by (c) mixing $H_{D}$ homopolymer $\left(\mathrm{PMVSOH}_{105}\right)$ with $\mathrm{N}-\mathrm{H}_{\mathrm{A}}-\mathrm{N}(540 \mathrm{~nm})$ triblock comicelles (hydroxyl/pyridyl group ratio = 5:1); and $\mathrm{H}_{\mathrm{D}}$ seeds $\left(\mathrm{M}\left(\mathrm{PFS}_{20}-b-\mathrm{PMVSOH}_{120}\right), 37 \mathrm{~nm}\right)$ with $\mathrm{N}-\mathrm{H}_{\mathrm{A}}-\mathrm{N}(1.4 \mu \mathrm{m}$ ) triblock comicelles (hydroxyl/pyridyl group ratio: (d) 20:1 and (e) 1:2) in $i$-PrOH. Insets in c and $\mathbf{d}$ are high magnification images of the $H_{A}$ segments after the adsorption of $H_{D}$ homopolymer and seeds, respectively. Scale bar, 500 or $100 \mathrm{~nm}$ (inset). Segments: $H_{A}=M\left(P F S_{32}-b-P 2 V P_{448}\right)$ and $N=M\left(P^{2} S_{20}-b-P_{B A} 280\right)$.

for $\mathrm{H}_{\mathrm{D}}-\mathrm{N}-\mathrm{H}_{\mathrm{D}}$ and $\mathrm{H}_{\mathrm{A}}-\mathrm{N}-\mathrm{H}_{\mathrm{A}}$, respectively. See Supplementary Fig. 1 and Supplementary Table 1). Figure 2a,b show TEM images of the ' $A B A$ ' and 'BAB' supermicelles using a hydroxyl/pyridyl group ratio of 3:1. However, the intermicellar H-bonding interactions were not fully controlled as 'branched' supermicelles were also detected (Supplementary Fig. 3a,b).

To achieve more effective confinement for the H-bonding interactions, the $\mathrm{H}_{\mathrm{A}}$ segments were placed at the centre of a triblock comicelle. Subsequent mixing of $\mathrm{H}_{\mathrm{D}}-\mathrm{N}-\mathrm{H}_{\mathrm{D}}$ and $\mathrm{N}-\mathrm{H}_{\mathrm{A}}-\mathrm{N}$ triblock comicelles (hydroxyl/pyridyl group ratio of 3:1) in $i$-PrOH led to ' $\mathrm{I}$-shaped supermicelles (Fig. 2c). The supermicelles could be extended in length to form dimer, trimer, tetramer and even 'polymeric' supermicelles (Fig. 2d-f; Supplementary Fig. 3c), but no branched structures were observed. When the $\mathrm{N}-\mathrm{H}_{\mathrm{A}}-\mathrm{N}$ triblock comicelles were in slight excess, predominantly 'I'-shaped supermicelles were produced (Supplementary Fig. 3d).

When the $\mathrm{H}_{\mathrm{D}}$ and $\mathrm{H}_{\mathrm{A}}$ segments were both placed in the centre of the triblock comicelles and the resulting $\mathrm{N}-\mathrm{H}_{\mathrm{D}}-\mathrm{N}$ and $\mathrm{N}-\mathrm{H}_{\mathrm{A}}-\mathrm{N}$ cylindrical comicelles mixed in $i$ - $\mathrm{PrOH}$ (hydroxyl/pyridyl group ratio of 2:1) 'cross' supermicelles were formed (Fig. 2g). Unsymmetrical examples were prepared using $\mathrm{N}-\mathrm{H}_{\mathrm{D}}-\mathrm{N}$ and $\mathrm{N}-\mathrm{H}_{\mathrm{A}}-\mathrm{N}$ triblock comicelles with different lengths with high efficiency (yield $=80 \%$; Fig. $2 \mathrm{~h}, \mathrm{i}$ ). This indicated that the balance between the attractive $\mathrm{H}$-bonding between the $\mathrm{H}_{\mathrm{D}}$ and $\mathrm{H}_{\mathrm{A}}$ central segments and the repulsive, steric interactions of the coronas of the terminal $\mathrm{N}$ segments led only to one-to-one complexes. However, when this balance was disturbed, no 'cross' supermicelles were formed. For example, compared with the samples shown in Fig. $2 \mathrm{~g}-\mathrm{i}$, when the P2VP coronal block for the central $\mathrm{H}_{\mathrm{A}}$ segment was reduced in length (from 448 to 250 repeat units) the weakened attraction between $\mathrm{H}_{\mathrm{D}}$ and $\mathrm{H}_{\mathrm{A}}$ segments was insufficient to generate 'cross' supermicelles (Supplementary Fig. 3e). In contrast, multiple-to-one complex 'cross' supermicelles were formed when an increased $\mathrm{H}_{\mathrm{A}}$ segment length was used $\left(109 \mathrm{~nm}\right.$, larger than the value of $L_{n}=45 \mathrm{~nm}$ in the cases of Fig. $2 \mathrm{~g}-\mathrm{i}$ ) in the $\mathrm{N}-\mathrm{H}_{\mathrm{A}}-\mathrm{N}$ triblock comicelles (Supplementary Fig. 3f).

Programmed stepwise hierarchical assembly. We also explored the use of a combination of H-bonding and solvophobic interactions to build even more complex, higher-level micelle architectures. First, $\mathrm{H}_{\mathrm{A}}-\mathrm{X}-\mathrm{H}_{\mathrm{A}}$ triblock comicelles with crosslinkable central segments were prepared by living CDSA. After switching to a more polar solvent via dialysis (from $i$ - $\mathrm{PrOH} / n$-hexane $=4: 1$ (v/v), to $\mathrm{MeOH}$ ), these triblock comicelles formed 'cross' supermicelles, due to the aggregation of $\mathrm{X}$ segments via solvophobic interactions (Fig. 3a). The yield of 'cross' supermicelles was ca. 90\% (Supplementary Fig. 4a). The X segments were then subject to covalent crosslinking ${ }^{40}$ using UV irradiation to create ${ }^{\mathrm{XL}} \mathrm{X}$ regions to make the 'cross' supermicelles permanent (Fig. 3b; Supplementary Fig. 4b). To build the next level of structure, $\mathrm{N}$ segments were grown from the four termini of these supermicelles by living CDSA (Fig. 3c; Supplementary Fig. 4c). To impart further robustness to the supermicelles and to hinder 


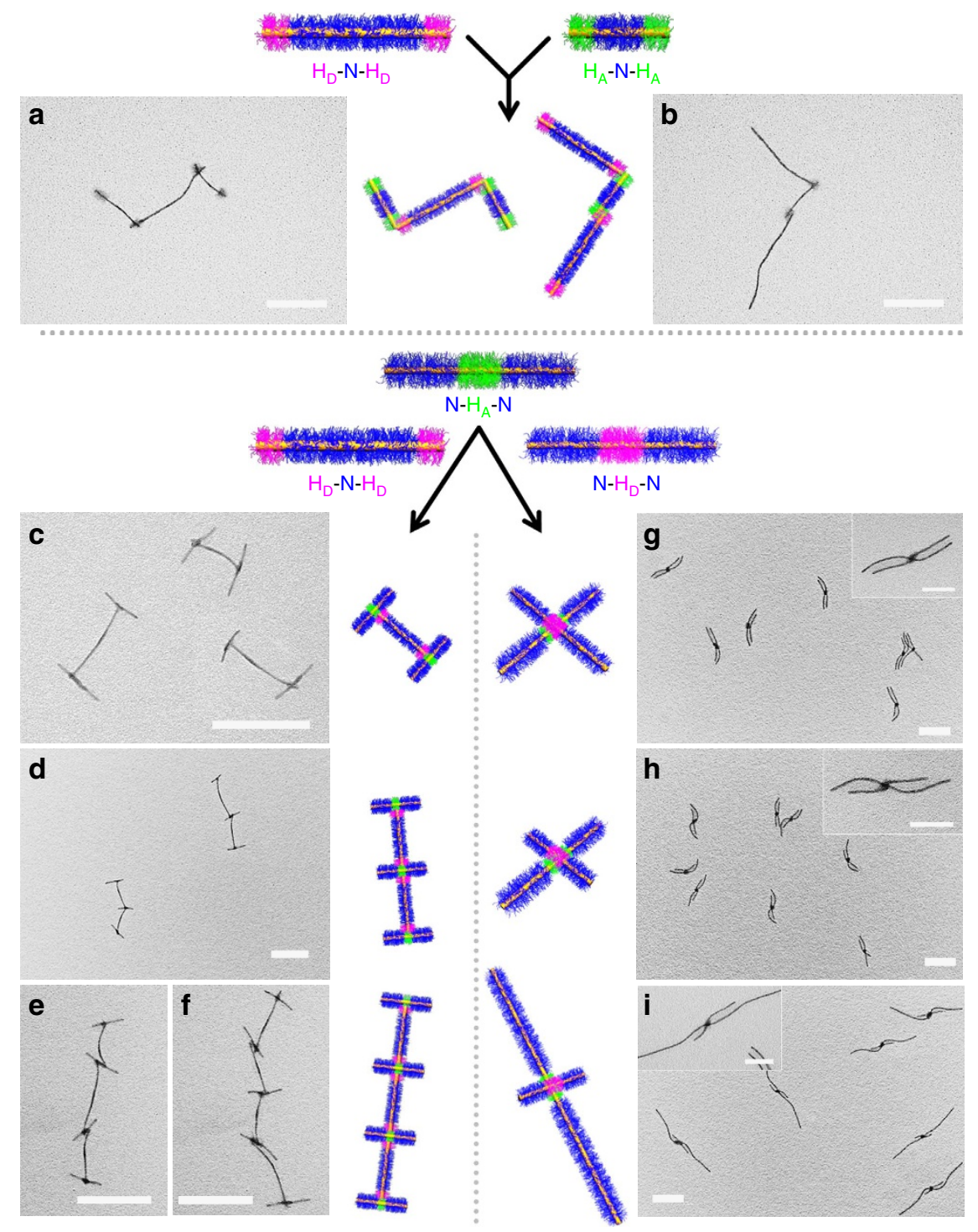

Figure 2 | Hierarchical assembly of triblock comicelles via H-bonding. TEM images (after solvent evaporation) and corresponding schematic representations of (a) 'ABA' and (b) 'BAB' supermicelles from $\mathrm{H}_{\mathrm{D}}-\mathrm{N}-\mathrm{H}_{\mathrm{D}}(910 \mathrm{~nm})$ and $\mathrm{H}_{\mathrm{A}}-\mathrm{N}-\mathrm{H}_{\mathrm{A}}(380 \mathrm{~nm}$ ) triblock comicelles (hydroxyl/pyridyl groups

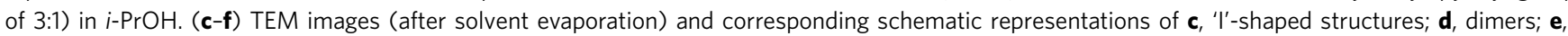
trimers; f, tetramers from $\mathrm{H}_{D}-\mathrm{N}-\mathrm{H}_{D}(480 \mathrm{~nm})$ and $\mathrm{N}-\mathrm{H}_{\mathrm{A}}-\mathrm{N}(320 \mathrm{~nm}$ ) triblock comicelles in $i-\mathrm{PrOH}$ (hydroxyl/pyridyl groups of 2:1). (g-i) TEM images (after solvent evaporation) of unsymmetrical micelles from $\mathrm{N}-\mathrm{H}_{\mathrm{D}}-\mathrm{N}$ and $\mathrm{N}-\mathrm{H}_{\mathrm{A}}-\mathrm{N}$ triblock comicelles in $i$-PrOH with total comicelle lengths of $\mathbf{g}$, 540 and $540 \mathrm{~nm} ; \mathbf{h}, 330$ and $540 \mathrm{~nm} ; \mathbf{i}, 330 \mathrm{~nm}$ and $1.3 \mu \mathrm{m}$, respectively. Scale bars are $500 \mathrm{~nm}$ and the scale bars in the insets are $200 \mathrm{~nm}$. Segment $\mathrm{H}_{\mathrm{D}}=\mathrm{M}\left(\mathrm{PFS}_{20}-b-\mathrm{PMVSOH}_{120}\right), \mathrm{H}_{\mathrm{A}}=\mathrm{M}\left(\mathrm{PFS}_{32}-b-\mathrm{P} 2 \mathrm{VP} \mathrm{P}_{48}\right)$ and $\mathrm{N}=\mathrm{M}\left(\mathrm{PFS}_{20}-b-\mathrm{PtBA}_{280}\right)$.

the acceptor ability of the P2VP chains during subsequent transformations, the $\mathrm{H}_{\mathrm{A}}$ coronal segments from the initial $\mathrm{H}_{\mathrm{A}}-\mathrm{X}-\mathrm{H}_{\mathrm{A}}$ triblock comicelle were crosslinked using Pt nanoparticles ${ }^{13}$ to yield $\mathrm{XL}_{\mathrm{H}_{\mathrm{A}}}$ segments (Fig. 3d; Supplementary Fig. 4d). As a result of the crosslinking, the electron density of ${ }^{\mathrm{XL}_{\mathrm{H}}} \mathrm{H}_{\mathrm{A}}$ and $\mathrm{XL}_{\mathrm{X}}$ segments increased and they appeared darker than the other regions by TEM. A further $\mathrm{H}_{\mathrm{A}}$ segment was then created at each of the cross supermicelle termini by living CDSA (Fig. 3e), and seeds with an $\mathrm{H}_{\mathrm{D}}$ corona were then added to bind to the uncrosslinked $\mathrm{H}_{\mathrm{A}}$ segments via $\mathrm{H}$-bonding (Fig. $3 \mathrm{f}$ ). The resulting composite 'cross' supermicelles were uniform in size and architecture, demonstrating the precision of this controlled hierarchical assembly method (see low resolution TEM images in Fig. 3g,h). To further illustrate the level of control, we grew $\mathrm{H}_{\mathrm{A}}$ segments with a longer P2VP corona-forming block at the termini of 'cross' supermicelles and we were then able to bind more $\mathrm{H}_{\mathrm{D}}$ seeds and to form larger bundles on the arms of composite 'cross' supermicelles (Supplementary Fig. 5a-c). Moreover, the bound $\mathrm{H}_{\mathrm{D}}$ seeds were found to be still active to living $\mathrm{CDSA}^{33}$ and addition of the PFS- $b$-PtBA unimer led to the formation of $\mathrm{N}$ segments (Fig. 4a). Interestingly, the subsequent growth of the $\mathrm{N}$ segments led to their mutual repulsion and resulted in a perpendicular alignment of the $\mathrm{N}-\mathrm{H}_{\mathrm{D}}-\mathrm{N}$ comicelles relative to the cross supermicelle arms. This afforded hierarchical 'windmill-like' supermicelles with high uniformity in size, architecture and yield (Fig. 4a,b; Supplementary Fig. 4e).

Direct characterization of the supermicelles in solution was achieved using laser scanning confocal microscopy (LSCM) analysis of 'windmill'-shaped supermicelle analogues with $\mathrm{N}$ segments labelled with red or green fluorescent BODIPY dyes. 'Cross' micelles with red-dye-labelled $\mathrm{N}$ segments in the arms were prepared first (Supplementary Fig. 5d-g). Finally, greendye-labelled $\mathrm{N}$ segments were grown from the $\mathrm{H}_{\mathrm{D}}$ seeds by living CDSA (Fig. 4c). A key issue for supramolecular, H-bonded 

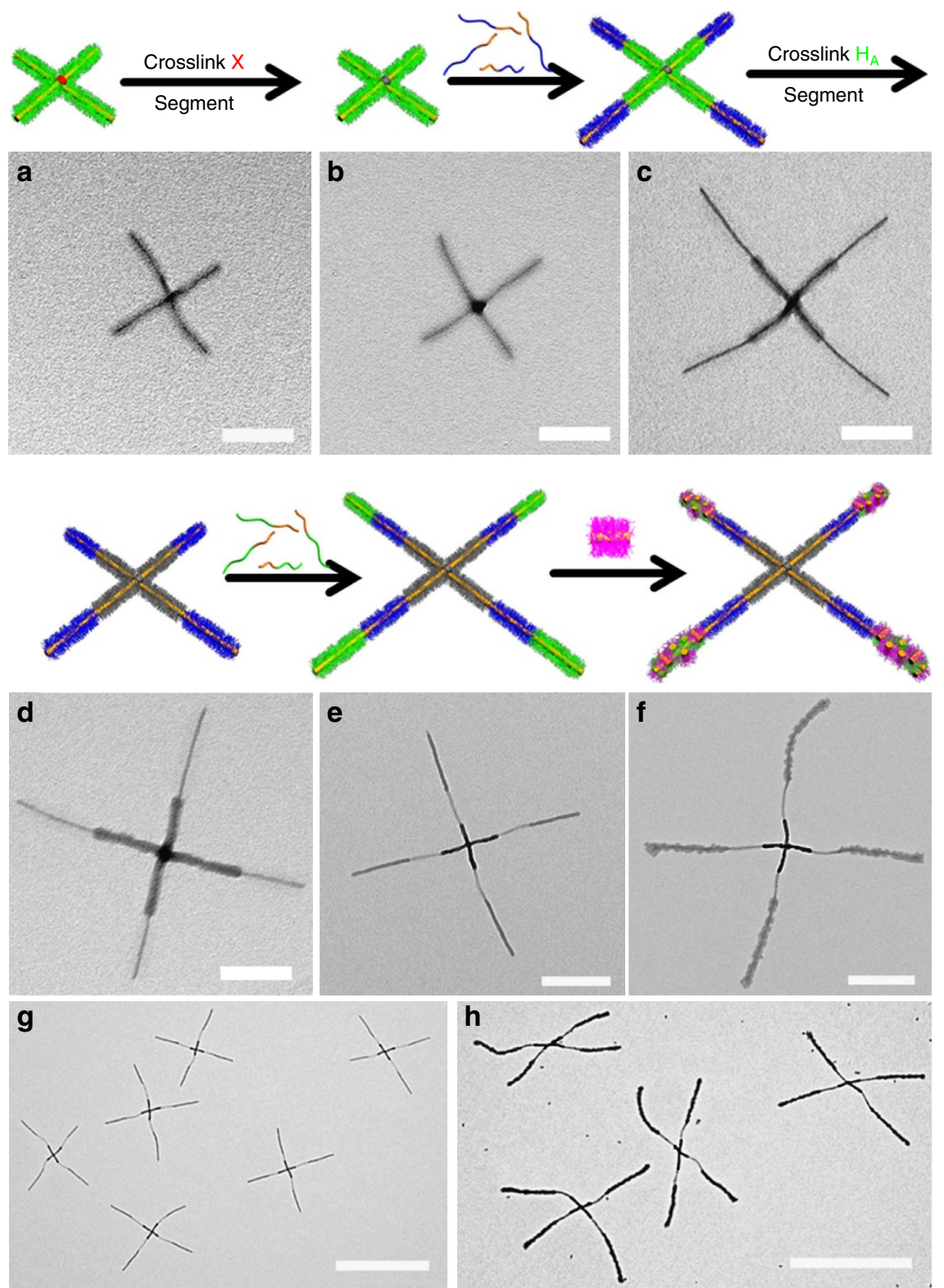

Figure 3 | Programmed stepwise hierarchical assembly. TEM images (after solvent evaporation) and corresponding schematic representations of (a) 'cross' supermicelles from the $\mathrm{H}_{\mathrm{A}}-\mathrm{X}-\mathrm{H}_{\mathrm{A}}(420 \mathrm{~nm})$ triblock comicelles; and the 'cross' supermicelles (b) with crosslinked ${ }^{X L} \mathrm{X}$ segments; (c) after the growth of $\mathrm{N}$ segments; (d) with crosslinked $\mathrm{XL}_{\mathrm{H}_{\mathrm{A}}}$ segments; (e) after the growth of another $\mathrm{H}_{\mathrm{A}}$ segments; and (f) after the further addition of $\mathrm{H}_{\mathrm{D}}$ seed micelles in $i-\mathrm{PrOH}$. Scale bars are $200 \mathrm{~nm}$ in images a-d, $500 \mathrm{~nm}$ in images (e,f) and $2 \mu \mathrm{m}$ in lower magnification images (g,h). Segment

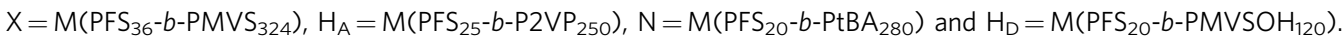

assemblies is their potential for dynamic behaviour. To explore the possible lability of the perpendicularly arranged $\mathrm{N}-\mathrm{H}_{\mathrm{D}}-\mathrm{N}$ comicelles near the termini of the 'cross' supermicelle arms, we mixed supermicelles in which the corresponding $\mathrm{N}$ segments possessed green dyes with analogues containing only red dyes in $i$-PrOH. No significant exchange between the two kinds of 'windmill' supermicelles was detected by LSCM even after 10 days at $22^{\circ} \mathrm{C}$, which indicated that they are static under these conditions and exist as kinetically stable, non-equilibrium structures (Fig. 4d; Supplementary Fig. 6g-j; for control experiments see Supplementary Fig. 6a-f).

\section{Discussion}

In summary, these results demonstrate the programmed formation of complex supermicelles by the use of confined regions of hydrogen bonding in cylindrical micelle precursors in orthogonal combination with crystallization and solvophobic interactions. This non-covalent synthesis approach allows the high-yield formation of hierarchical architectures that are persistent in solution, kinetically stable, easy to functionalise and sufficiently robust to allow for further processing. Additional stabilization can also be introduced through covalent crosslinking methods. The novel architectures accessible may be useful as models of biological structures (for example, chromosomes in the case of unsymmetrical crossmicelles) or as tectons for the creation of yet more complex hierarchical materials. As the living CDSA method used to create the micelle-building blocks has been shown to be applicable to a variety of crystallizable block copolymers and related $\pi$-stacking molecular amphiphiles, including those based on electroactive ${ }^{41-45}$, bioactive $\mathrm{u}^{46,47}$ and bioinert ${ }^{48}$ characteristics, potential future applications for the resulting assemblies in sensing, nanoelectronics, catalysis and biomedicine can be envisaged. 


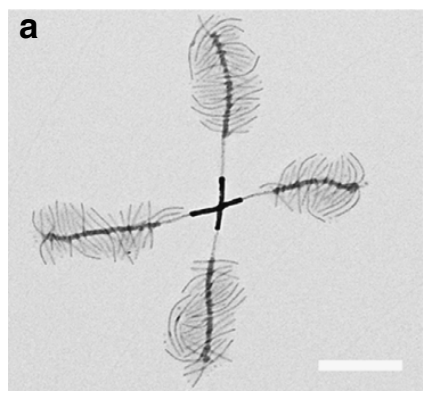

b
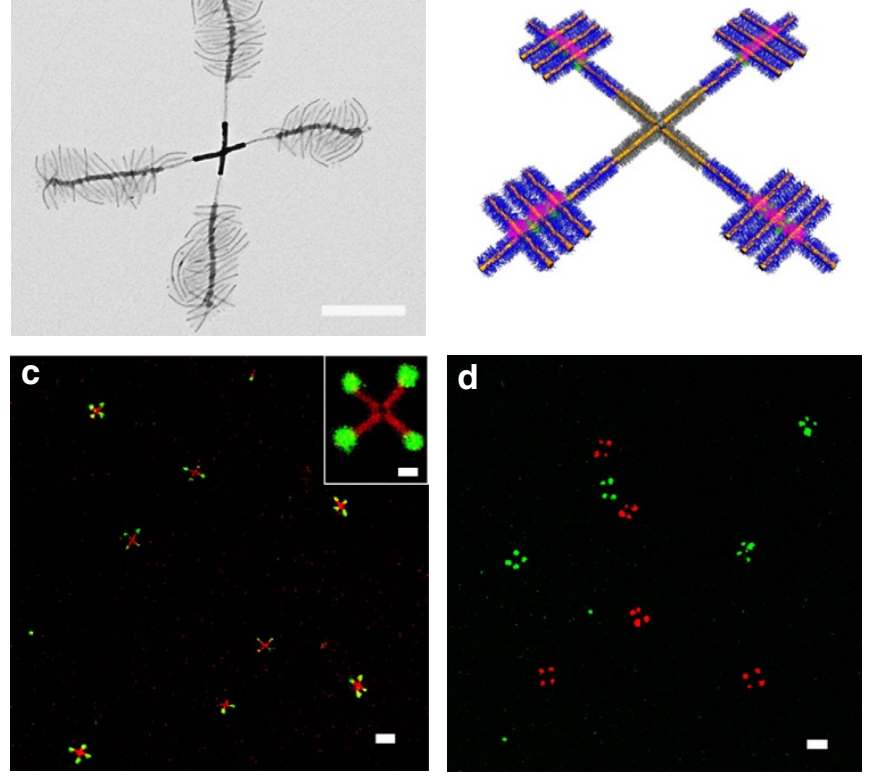

Figure 4 | 'Windmill'-like supermicelles. (a) TEM image (after solvent evaporation) of a 'windmill'-like supermicelle formed in $i-\mathrm{PrOH}$.

(b) Schematic illustration of the supermicelles. (c) LSCM image of fluorescent dye-labelled large 'supermicelles' with the inner $\mathrm{N}$ segments labelled with a red dye and the outer $\mathrm{N}$ segments labelled with a green dye in $i-\mathrm{PrOH}$. Inset is a zoom-in LSCM image of a 'windmill'-like supermicelle. (d) LSCM images of the mixture of 'windmill'-shaped supermicelles labelled with either red or green dyes (after 10 days at $22^{\circ} \mathrm{C}$ ) in $i-\mathrm{PrOH}$. Scale bars are $500 \mathrm{~nm}$ in (a), $5 \mu \mathrm{m}$ in (c,d) and $1 \mu \mathrm{m}$ in the inset.

\section{Methods}

Polymer synthesis. The diblock copolymers used in this study were synthesized via anionic polymerization in an inert atmosphere glovebox. The detailed polymerization procedures for these polymers have been reported elsewhere ${ }^{49-51}$. The PFS- $b$-PMVSOH polymer was prepared from PFS- $b$-PMVS polymer via a thiol-ene click reaction (with 2-mercaptoethanol), which has been reported recently by our group $^{52}$.

Fluorescent dye-labelled PFS- $b$-PtBA was obtained by post-polymerization modification. The PFS- $b$-PtBA precursor with a hydroxyl terminal group was synthesized via anionic polymerization and the anions were quenched with ethylene oxide and subsequently with 4-tert-butylphenol (yield $99 \%$ by ${ }^{1} \mathrm{H}$ NMR). Green dye (BODIPY FL, $3 \mathrm{mg}, 8 \times 10^{-3} \mathrm{mmol}$ of carboxyl groups) ${ }^{38}$ was mixed with $80 \mathrm{mg}$ of the PFS- $b$-PtBA with a hydroxyl terminal group $\left(2 \times 10^{-3} \mathrm{mmol}\right.$ of hydroxyl groups), $1 \mathrm{mg}$ of dicyclohexylcarbodiimide $\left(8 \times 10^{-3} \mathrm{mmol}\right)$ and $0.8 \mathrm{mg}$ of 4 -dimethylaminopyridine $\left(1 \times 10^{-3} \mathrm{mmol}\right)$ in dry tetrahydrofuran (THF) $(2 \mathrm{ml})^{38}$. The solution was stirred at room temperature for 3 days before the polymer was precipitated into a mixed solvent of $\mathrm{MeOH}$ and water $(8: 2, \mathrm{v} / \mathrm{v})$ for three times and further by dialysis against THF. The red dye-containing polymer was prepared the same way except BODIPY $630 / 650$ was used ${ }^{38}$.

Polymer characterization. Gel permeation chromatography (GPC) measurements were carried out on a Viscotek VE 2001 triple-detector gel permeation chromatograph equipped with an automatic sampler, a pump, an injector, an inline degasser and a column oven $\left(30^{\circ} \mathrm{C}\right)$. The elution columns consist of styrene/divinyl benzene gels with pore sizes of 500 and 100,000 A. Detection was conducted by means of a VE 3580 refractometer, a four-capillary differential viscometer, and $90^{\circ}$ and low angle $\left(7^{\circ}\right)$ laser light $\left(\lambda_{0}=670 \mathrm{~nm}\right)$ scattering detectors, VE 3210 and VE 270. THF (Fisher) was used as the eluent, with a flow rate of $1.0 \mathrm{ml} \mathrm{min}^{-1}$. Samples were dissolved in the eluent $\left(2 \mathrm{mg} \mathrm{ml}^{-1}\right)$ and filtered with a Ministart SRP 15 filter (polytetrafluoroethylene membrane of $0.45 \mu \mathrm{m}$ pore size) before analysis. The calibration was conducted using a PolyCALTM polystyrene standard from Viscotek. To determine the molar mass of the block copolymers, aliquots of the first block were taken and the molar mass of the first block was determined by gel permeation chromatography. The polymerization degrees of the two blocks were then determined by combining the molecular weight $M_{n}$ of the first block with the block ratio of the diblock copolymer, which was obtained by integration of the ${ }^{1} \mathrm{H}$ NMR spectrum. Polydispersities of the PFS homopolymers and block copolymers were in the range 1.081.16 by GPC.
Transmission electron microscopy. Copper grids from Agar Scientific, mesh 400, were coated with a carbon film. Carbon coating was done using an Agar TEM Turbo Carbon Coater in which carbon was sputtered onto mica sheets before deposition on the grids via flotation on water. The samples for electron microscopy were prepared by drop-casting one drop $(\sim 10 \mu \mathrm{l})$ of the micelle colloidal solution onto a carbon-coated copper grid. Bright-field TEM micrographs were obtained on a JEOL 1200-EX II microscope operating at $120 \mathrm{kV}$ and equipped with an SIS MegaView III digital camera. Images were analysed using the ImageJ software package developed at the US National Institutes of Health. As the micelles reported here are trapped kinetically because of crystallization of the core block, the morphologies observed from dried samples by TEM are anticipated to match closely those observed in solution, as previously shown for 1D systems ${ }^{36}$. For the statistical length analysis, 300-400 objects were measured to determine the contour length. Histograms of the length distribution were constructed. From these data, values of the s.d. of the length distribution 'sigma' were determined. The number average micelle length $\left(L_{n}\right)$ and weight average micelle length $\left(L_{w}\right)$ were calculated using the equations (1) and (2) below from measurements of the contour lengths $\left(L_{i}\right)$ of individual micelles, where $N_{i}$ is the number of micelles of length $L_{i}$, and $n$ is the number of micelles examined in each sample.

$$
\begin{array}{r}
L_{n}=\frac{\sum_{i=1}^{n} N_{i} L_{i}}{\sum_{i=1}^{n} N_{i}} \\
L_{w}=\frac{\sum_{i=1}^{n} N_{i} L_{i}^{2}}{\sum_{i=1}^{n} N_{i} L_{i}}
\end{array}
$$

The distribution of micelle lengths is characterized by both $L_{w} / L_{n}$ and the ratio $\sigma /$ $L_{n}$, where $\sigma$ is the s.d. of the length distribution.

Experimental evidence for $\mathbf{H}$-bonding interactions. $\mathrm{PMVSOH}_{192}$ and $\mathrm{P}_{2} \mathrm{VP}_{20}$ homopolymers were dried from their $i$ - $\mathrm{PrOH}$ solution and dried in vacuum oven before characterization. The mixture of PMVSOH and P2VP (mole ratio of hydroxyl/pyridyl group $=1: 1$ ) was prepared by mixing the two solutions and dried before characterization.

Fourier Transform Infrared (FTIR) spectra were recorded with an attenuated total reflection accessory. As can be seen from Supplementary Fig. 2o, a new peak appeared at $3,264 \mathrm{~cm}^{-1}$ after mixing the two homopolymers suggesting the formation of $\mathrm{H}$-bonds ${ }^{53,54}$. The peak at $3,390 \mathrm{~cm}^{-1}$ originated from the residual $i$ $\mathrm{PrOH}$ molecules and the homopolymers $(\mathrm{O}-\mathrm{H}$ stretching of $\mathrm{H}$-bonded and free hydroxyl groups). The peaks at 1,565 and $1,580 \mathrm{~cm}^{-1}$ (from P2VP homopolymer as shown in Supplementary Fig. 2p), corresponding to the stretching of double bonds in the pyridine ring, shifted to 1,631 and $1,658 \mathrm{~cm}^{-1}$ after mixing with PMVSOH homopolymers, a typical response to hydrogen bonding of pyridine ring $^{54,55}$.

Preparation of seed cylinders. Seed cylinders were prepared by ultrasonicating ( $50 \mathrm{~W}$ sonication processor equipped with a titanium sonotrode) the block copolymer cylinders at low temperatures. PFS- $b$-PMVS seed cylinders were obtained via sonication at $-78^{\circ} \mathrm{C}$ for $1 \mathrm{~h}$ in $n$-hexane, and sonication at $0{ }^{\circ} \mathrm{C}$ for $1 \mathrm{~h}$ in $i$-PrOH was used to obtain other seed cylinders (M(PFS- $b$-P2VP) and $\mathrm{M}(\mathrm{PFS}-b$-PMVSOH $)$ ). The original cylinders were obtained by directly dispersing the diblock copolymers into the corresponding solvents and heating at $70{ }^{\circ} \mathrm{C}$ for $1 \mathrm{~h}$ before the solution was allowed to cool to room temperature. The lengths of seed cylinders could be increased by adding a solution of fresh unimers (the polymer dissolved in THF) into the seed micelle solution.

Preparation of triblock comicelles. The triblock comicelles were prepared via the seeded growth method. For example, to prepare triblock comicelle $\mathrm{M}\left(\mathrm{PFS}_{20}-b-\mathrm{PtBA}_{280}\right)-b-\mathrm{M}\left(\mathrm{PFS}_{32}-b-\mathrm{P}_{2} \mathrm{VP}_{448}\right)-b-\mathrm{M}\left(\mathrm{PFS}_{20}-b-\mathrm{PtBA}_{280}\right), 0.1 \mathrm{ml}$ of $\mathrm{M}\left(\mathrm{PFS}_{32}-b-\mathrm{P}_{2} \mathrm{VP}_{448}\right)$ seed cylinders $i$-PrOH solution $\left(0.5 \mathrm{mg} \mathrm{ml}^{-1}\right)$ was diluted with $0.4 \mathrm{ml}$ of $i-\mathrm{PrOH}$, and then $5 \mu \mathrm{l}$ of a THF solution of $\mathrm{PFS}_{20}-b-\mathrm{PtBA}_{280}$ unimers was added. The $\mathrm{PFS}_{20}-b-\mathrm{PtBA}_{280}$ unimers then grew epitaxially from the active termini of the $\mathrm{M}\left(\mathrm{PFS}_{32}-b-\mathrm{P}_{2} \mathrm{VP}_{448}\right)$ seed cylinders to form triblock comicelles.

Preparation of supermicelles via $\mathbf{H}$-bonding interactions. Two kinds of cylinders, one bearing M(PFS- $b$-P2VP) segments and the other bearing M(PFS- $b$ $\mathrm{PMVSOH}$ ) segments were mixed with each other at the desired feed ratio in $i$-PrOH. The solution was gently shaken for $20 \mathrm{~s}$ and kept still overnight before analysis by TEM.

The resulting supermicelles (such as those shown in Fig. 1c, the large micelle bundles in Fig. 1e and the linear 'oligomers' in Fig. 2c-f) were reproducibly formed as a distribution of very closely related structures (for example, see low resolution TEM images in Supplementary Figs $2 \mathrm{c}, \mathrm{n}$ and 3). For example, in the case of the micelle bundles, these were relatively uniform in size but the aggregation number (that is, arm distribution) generally varied between 5 and 10 .

The yields of the simple symmetrical 'cross' micelles and unsymmetrical 'cross' micelles (Fig. 2) by TEM were ca. 80 and $90 \%$, respectively. 
Preparation of complex 'cross' and 'windmill' supermicelles. The first level 'cross' supermicelles prepared from $\mathrm{H}_{\mathrm{A}}-\mathrm{N}-\mathrm{H}_{\mathrm{A}}$ triblock comicelle $\left(\mathrm{M}\left(\mathrm{PFS}_{25}-b\right.\right.$ $\left.\left.\mathrm{P}_{2} \mathrm{VP}_{250}\right)-b-\mathrm{M}\left(\mathrm{PFS}_{36}-b-\mathrm{PMVS}_{324}\right)-b-\mathrm{M}\left(\mathrm{PFS}_{25}-b-\mathrm{P}_{2} \mathrm{VP}_{250}\right)\right)$, which were initially prepared in a mixed solvent consisting of $n$-hexane $/ i-\mathrm{PrOH}=1: 4(\mathrm{v} / \mathrm{v})$ by the seeded growth method. The solvent was slowly switched to $\mathrm{MeOH}$ by changing the solvent stepwise (100\% of $i-\mathrm{PrOH}, i-\mathrm{PrOH} / \mathrm{MeOH}=8: 2,6: 4,4: 6,2: 8$ and eventually $100 \%$ of $\mathrm{MeOH}$ ). This slow solvent switching protocol was designed to gradually induce the aggregation of insoluble block and thus the formation of 'cross' supermicelles. By counting from TEM images, ca. $80 \%$ of the objects observed from TEM are 'cross' supermicelles. Most of ( $c$ a. 90\%) the $\mathrm{H}_{\mathrm{A}}-\mathrm{N}-\mathrm{H}_{\mathrm{A}}$ triblock comicelles formed 'cross' supermicelles, and the others either remained as individual cylindrical comicelles in the solution or formed larger aggregates consisting of multiple triblock comicelles.

The $\mathrm{MeOH}$ solution of the 'cross' supermicelles $(1.0 \mathrm{ml})$ was degassed by $\mathrm{N}_{2}$ bubbling for $30 \mathrm{~min}$ before being transferred into a glovebox, where $10 \mu \mathrm{l}$ of 2,2 dimethoxy-2-phenylacetophenone in $\mathrm{MeOH}(10 \mathrm{mg} / \mathrm{ml})$ was added. The solution was subsequently subjected to UV irradiation for $30 \mathrm{~min}$ with occasional agitation. The collapsed and densely packed PMVS chains were crosslinked on UV irradiation.

After crosslinking of the PMVS block, the sample solution was dialyzed against $i$ - $\mathrm{PrOH}$ to remove $\mathrm{MeOH}$. After crosslinking, the 'cross' supermicelles were stable in $i$-PrOH (Supplementary Fig. $4 \mathrm{~b})$. $\mathrm{M}\left(\mathrm{PFS}_{20}-b-\mathrm{PtBA}_{280}\right)$ segments were grown via seeded growth by adding THF solution of $\mathrm{PFS}_{20}-b-\mathrm{PtBA}_{280}$ unimers into the solution. The $\mathrm{M}\left(\mathrm{PFS}_{25}-b-\mathrm{P}_{2} \mathrm{VP}_{250}\right)$ segments were further crosslinked by Karstedt's catalyst. Typically, a mass ratio of 1:2 (pyridyl to $\mathrm{Pt}$ ) was used. Subsequently, another $\mathrm{M}\left(\mathrm{PFS}_{25}-b-\mathrm{P}_{2} \mathrm{VP}_{250}\right)$ segment was grown onto the open termini of the $\mathrm{M}\left(\mathrm{PFS}_{20}-b-\mathrm{PtBA}_{280}\right)$ segments via seeded growth, after which $\mathrm{M}\left(\mathrm{PFS}_{20}-b-\right.$ $\mathrm{PMVSOH}_{120}$ ) seeds were added into the solution with a ratio of 25:1 (hydroxyl/ pyridyl). The $\mathrm{M}\left(\mathrm{PFS}_{20}-b\right.$ - $\left.\mathrm{PMVSOH}_{120}\right)$ seeds adsorbed onto the uncrosslinked $\mathrm{M}\left(\mathrm{PFS}_{25}-b\right.$ - $\left.\mathrm{P}_{2} \mathrm{VP}_{250}\right)$ segments due to H-bonding interactions. Into the solution fresh $\mathrm{PFS}_{20}-b$ - $\mathrm{PtBA}_{280}$ was added again, which grew from the open termini, and finally 'windmill'-shaped supermicelles were obtained.

As a result of the efficiency of living CDSA, the 'cross' supermicelles were successfully and quantitatively converted into 'windmill' supermicelles based on TEM images. Thus, about $90 \%$ of the supermicelles were 'windmill' supermicelles. However, to avoid having the $\mathrm{H}_{\mathrm{D}}$ seeds interact with multiple composite 'cross' supermicelles, a slight excess of $H_{D}$ seeds was used (Fig. 3f,h). The $H_{D}$ seeds that did not become attached to the composite 'cross' supermicelles were also able to initiate the growth of $\mathrm{N}$ segments and form $\mathrm{N}-\mathrm{H}_{\mathrm{D}}-\mathrm{N}$ triblock comicelles once PFS$b$-PtBA unimers were added into the solution (Supplementary Fig. 4e, marked with red circles). Thus, by counting from TEM images, $c a$. $75 \%$ of the objects observed from TEM were 'windmill' supermicelles. By counting the individual $\mathrm{N}-\mathrm{H}_{\mathrm{D}}-\mathrm{N}$ triblock comicelles and those present on the 'windmill' supermicelles from TEM images, we estimate that $c a$. $95 \%$ of the $\mathrm{N}-\mathrm{H}_{\mathrm{D}}-\mathrm{N}$ triblock comicelles present were incorporated into the 'windmill' supermicelles.

Preparation of fluorescent 'windmill' supermicelles. The fluorescent 'windmill' supermicelles were prepared in the same way as the normal ones, except fluorescent dye-containing $\mathrm{PFS}_{20}-b-\mathrm{PtBA}_{280}$ unimers were used. Specifically, after the crosslinking of the $\mathrm{H}_{\mathrm{A}}$ segments, as shown in Fig. 3d, dye-terminated $\mathrm{PFS}_{20}-b$ - $\mathrm{PtBA}_{280}$-red unimers were added to extend the PFS- $b$-PtBA arms. Subsequently, $\mathrm{PFS}_{25}-\mathrm{b}-\mathrm{P}_{2} \mathrm{VP}_{250}$ unimers were added to further extend the arms, after which $\mathrm{M}\left(\mathrm{PFS}_{20}-b\right.$ - $\left.\mathrm{PMVSOH}_{120}\right)$ seeds were added into the solution with a ratio of 25:1 (hydroxyl/pyridyl). The $\mathrm{M}\left(\mathrm{PFS}_{20}-b-\mathrm{PMVSOH}_{120}\right)$ seeds adsorbed onto the uncrosslinked $\mathrm{M}\left(\mathrm{PFS}_{25}-b-\mathrm{P}_{2} \mathrm{VP}_{250}\right)$ segments. Finally, dye-terminated $\mathrm{PFS}_{20^{-}}-b$ $\mathrm{PtBA}_{280}$ unimers were added into the solution to generate the final 'windmill' supermicelles.

General techniques. Photolysis experiments were carried out with Pyrex-glass filtered emission from a water-cooled, $125-\mathrm{W}$ medium-pressure mercury lamp (Photochemical Reactors Ltd.), emitting predominantly $365 \mathrm{~nm}$. The emission lines of the mercury lamp were $577-579,546,436,408-405,366-365,334,313,302$, $297,289,280,270,265$ and $254 \mathrm{~nm}$. An ethylene glycol/deionized water bath in conjunction with a thermostat was used to maintain constant temperatures during photoirradiation. All the photoreactions were carried out at $20^{\circ} \mathrm{C}$

All the ${ }^{1} \mathrm{H}$ NMR characterization was carried out on a Varian $400 \mathrm{MHz}$ instrument, with chemical shifts referenced to tetramethylsilane in $d$-chloroform $\left(\mathrm{CDCl}_{3}\right)$. FTIR spectra were recorded with Cary 630 FTIR spectrometer fitted with an attenuated total reflection accessory (Agilent Technologies).

Confocal fluorescence microscopy. Confocal imaging was performed using a Leica SP5 system attached to a Leica DMI6000 inverted epifluorescence microscope with a $\times 63$ (NA 1.4) oil immersion objective lens. Fluorophores from PFS- $b$ PtBA-red and PFS- $b$-PtBA-green were excited using a HeNe laser operating at $594 \mathrm{~nm}$ and an argon laser operating at $488 \mathrm{~nm}$, respectively. Confocal images were obtained using digital detectors with observation windows of $605-700 \mathrm{~nm}$ for the red dye and $500-570 \mathrm{~nm}$ for the green dye. The resulting outputs were obtained as digital false-colour images, which are colour coded using the chromaticity of each micelle block under UV irradiation at $365 \mathrm{~nm}$, as observed by fluorescence spectroscopy. For imaging of multicomponent supermicelles, the output power of each laser was varied until the fluorescence of all blocks could be observed at approximately equal brightness.

\section{References}

1. Fratzl, P. \& Weinkamer, R. Nature's hierarchical materials. Prog. Mater. Sci. 52, 1263-1334 (2007).

2. Whitesides, G. M. \& Grzybowski, B. Self-assembly at all scales. Science 295, 2418-2421 (2002).

3. Mann, S. Self-assembly and transformation of hybrid nano-objects and nanostructures under equilibrium and non-equilibrium conditions. Nat. Mater. 8, 781-792 (2009).

4. Glotzer, S. C. \& Solomon, M. J. Anisotropy of building blocks and their assembly into complex structures. Nat. Mater. 6, 557-562 (2007).

5. Zhang, L. F. \& Eisenberg, A. Multiple morphologies of crew-cut aggregates of polystyrene- $b$-poly(acrylic acid) block-copolymers. Science 268, 1728-1731 (1995).

6. Zhang, L. F., Yu, K. \& Eisenberg, A. Ion-induced morphological changes in "crew-cut" aggregates of amphiphilic block copolymers. Science 272, 1777-1779 (1996).

7. Pochan, D. J. et al. Toroidal triblock copolymer assemblies. Science 306, 94-97 (2004).

8. Cui, H. G., Chen, Z. Y., Zhong, S., Wooley, K. L. \& Pochan, D. J. Block copolymer assembly via kinetic control. Science 317, 647-650 (2007).

9. Li, Z. B., Kesselman, E., Talmon, Y., Hillmyer, M. A. \& Lodge, T. P. Multicompartment micelles from ABC miktoarm stars in water. Science 306, 98-101 (2004)

10. Dupont, J., Liu, G. J., Niihara, K., Kimoto, R. \& Jinnai, H. Self-assembled ABC triblock copolymer double and triple helices. Angew. Chem. Int. Ed. 48, 6144-6147 (2009).

11. Erhardt, R. et al. Amphiphilic Janus micelles with polystyrene and poly(methacrylic acid) hemispheres. J. Am. Chem. Soc. 125, 3260-3267 (2003).

12. Gröschel, A. H. et al. Facile, solution-based synthesis of soft, nanoscale Janus particles with tunable Janus balance. J. Am. Chem. Soc. 134, 13850-13860 (2012).

13. Cheng, L., Zhang, G. Z., Zhu, L., Chen, D. Y. \& Jiang, M. Nanoscale tubular and sheetlike superstructures from hierarchical self-assembly of polymeric Janus particles. Angew. Chem. Int. Ed. 47, 10171-10174 (2008).

14. Nie, L., Liu, S. Y., Shen, W. M., Chen, D. Y. \& Jiang, M. One-pot synthesis of amphiphilic polymeric Janus particles and their self-assembly into supermicelles with a narrow size distribution. Angew. Chem. Int. Ed. 46, 6321-6324 (2007).

15. Walther, A. et al. Self-assembly of Janus cylinders into hierarchical superstructures. J. Am. Chem. Soc. 131, 4720-4728 (2009).

16. Fang, B. et al. Undulated multicompartment cylinders by the controlled and directed stacking of polymer micelles with a compartmentalized corona. Angew. Chem. Int. Ed. 48, 2877-2880 (2009).

17. Gröschel, A. H. et al. Precise hierarchical self-assembly of multicompartment micelles. Nat. Commun. 3, 710 (2012).

18. Gröschel, A. H. et al. Guided hierarchical co-assembly of soft patchy nanoparticles. Nature 503, 247-251 (2013).

19. Qiu, H. B., Hudson, Z. M., Winnik, M. A. \& Manners, I. Multidimensional hierarchical self-assembly of amphiphilic cylindrical block comicelles. Science 347, 1329-1332 (2015).

20. Kostiainen, M. A., Kasyutich, O., Cornelissen, J. J. L. M. \& Nolte, R. J. M. Selfassembly and optically triggered disassembly of hierarchical dendron-virus complexes. Nat. Chem. 2, 394-399 (2010).

21. Hirschberg, J. H. K. K. et al. Helical self-assembled polymers from cooperative stacking of hydrogen-bonded pairs. Nature 407, 167-170 (2000).

22. Prins, L. J., De Jong, F., Timmerman, P. \& Reinhoudt, D. N. An enantiomerically pure hydrogen-bonded assembly. Nature 408, 181-184 (2000).

23. Sijbesma, R. P. et al. Reversible polymers formed from self-complementary monomers using quadruple hydrogen bonding. Science 278, 1601-1604 (1997).

24. Hartgerink, J. D., Beniash, E. \& Stupp, S. I. Self-assembly and mineralization of peptide-amphiphile nanofibers. Science 294, 1684-1688 (2001).

25. Albertazzi, L. et al. Probing exchange pathways in one-dimensional aggregates with super-resolution microscopy. Science 344, 491-495 (2014).

26. Douglas, S. M. et al. Self-assembly of DNA into nanoscale three-dimensional shapes. Nature 459, 414-418 (2009).

27. Lo, P. K. et al. Loading and selective release of cargo in DNA nanotubes with longitudinal variation. Nat. Chem. 2, 319-328 (2010).

28. Goodman, R. P. et al. Rapid chiral assembly of rigid DNA building blocks for molecular nanofabrication. Science 310, 1661-1665 (2005).

29. Valkama, S. et al. Self-assembled polymeric solid films with temperatureinduced large and reversible photonic-bandgap switching. Nat. Mater. 3, 872-876 (2004). 
30. Ruokolainen, J. et al. Switching supramolecular polymeric materials with multiple length scales. Science 280, 557-560 (1998).

31. Zhao, Y. et al. Small-molecule-directed nanoparticle assembly towards stimuliresponsive nanocomposites. Nat. Mater. 8, 979-985 (2009).

32. Tang, C. B., Lennon, E. M., Fredrickson, G. H., Kramer, E. J. \& Hawker, C. J. Evolution of block copolymer lithography to highly ordered square arrays. Science 322, 429-432 (2008).

33. Jia, L. et al. A design strategy for the hierarchical fabrication of colloidal hybrid mesostructures. Nat. Commun. 5, 3882 (2014).

34. Hudson, Z. M., Lunn, D. J., Winnik, M. A. \& Manners, I. Colour-tunable fluorescent multiblock micelles. Nat. Commun. 5, 3372 (2014).

35. Rupar, P. A., Chabanne, L., Winnik, M. A. \& Manners, I. Non-centrosymmetric cylindrical micelles by unidirectional growth. Science 337, 559-562 (2012).

36. Wang, X. S. et al. Cylindrical block copolymer micelles and co-micelles of controlled length and architecture. Science 317, 644-647 (2007).

37. Gilroy, J. B. et al. Monodisperse cylindrical micelles by crystallization-driven living self-assembly. Nat. Chem. 2, 566-570 (2010).

38. Hudson, Z. M. et al. Tailored hierarchical micelle architectures using living crystallization-driven self-assembly in two dimensions. Nat. Chem. 6, 893-898 (2014).

39. Freitas, L. D., Jacobi, M. M., Gonçalves, G. \& Stadler, R. Microphase separation induced by hydrogen bonding in a poly(1,4-butadiene)-block-poly(1,4isoprene) diblock copolymers-an example of supramolecular organization via tandem interactions. Macromolecules 31, 3379-3382 (1998).

40. O’Reilly, R. K., Hawker, C. J. \& Wooley, K. L. Cross-linked block copolymer micelles: functional nanostructures of great potential and versatility. Chem. Soc. Rev. 35, 1068-1083 (2006)

41. Qian, J. et al. Uniform, high aspect ratio fiber-like micelles and block co-micelles with a crystalline pi-conjugated polythiophene core by self-seeding. J. Am. Chem. Soc. 136, 4121-4124 (2014).

42. Zhang, W. et al. Supramolecular linear heterojunction composed of graphitelike semiconducting nanotubular segments. Science 334, 340-343 (2011).

43. Ogi, S., Sugiyasu, K., Manna, S., Samitsu, S. \& Takeuchi, M. Living supramolecular polymerization realized through a biomimetic approach. Nat. Chem. 6, 188-195 (2014).

44. Bu, L., Dawson, T. J. \& Hayward, R. C. Tailoring ultrasound-induced growth of perylene diimide nanowire crystals from solution by modification with poly(3-hexyl thiophene). ACS Nano 9, 1878-1885 (2015).

45. Görl, D., Zhang, X., Stepanenko, V. \& Würthner, F. Supramolecular block copolymers by kinetically controlled co-self-assembly of planar and coretwisted perylene bisimides. Nat. Commun. 6, 7009 (2015).

46. Pal, A. et al. Controlling the structure and length of self-synthesizing supramolecular polymers through nucleated growth and disassembly. Angew. Chem. Int. Ed. 54, 7852 (2015).

47. Sun, L. et al. Structural reorganization of cylindrical nanoparticles triggered by polylactide stereocomplexation. Nat. Commun. 5, 6746 (2014).

48. Schmelz, J., Schedl, A. E., Steinlein, C., Manners, I. \& Schmalz, H. Length control and block-type architectures in worm-like micelles with polyethylene cores. J. Am. Chem. Soc. 134, 14217-14225 (2012).

49. Massey, J. A. et al. Self-assembly of organometallic block copolymers: the role of crystallinity of the core-forming polyferrocene block in the micellar morphologies formed by poly(ferrocenylsilane- $b$-dimethylsiloxane) in n-alkane solvents. J. Am. Chem. Soc. 122, 11577-11584 (2000).
50. Wang, H., Winnik, M. A. \& Manners, I. Synthesis and self-assembly of poly(ferrocenyldimethylsilane- $b$-2-vinylpyridine) diblock copolymers. Macromolecules 40, 3784-3789 (2007).

51. McGrath, N. et al. Synthesis and crystallization-driven solution self-assembly of polyferrocenylsilane diblock copolymers with polymethacrylate coronaforming blocks. Polym. Chem. 5, 1923-1929 (2014).

52. Lunn, D. J. et al. Controlled thiol-ene functionalization of polyferrocenylsilaneblock-polyvinylsiloxane copolymers. Macromol. Chem. Phys. 214, 2813-2820 (2013).

53. Lee, L.-T., Woo, E. M., Hou, S. S. \& Förster, S. Miscibility with positive deviation in $T_{\mathrm{g}}$-composition relationship in blends of poly(2-vinyl pyridine)block-poly(ethylene oxide) and poly( $p$-vinyl phenol). Polymer 47, 8350-8359 (2006).

54. Cesteros, L. C., Isasi, J. R. \& Katime, I. Hydrogen-bonding in poly(4vinylpyridine)/poly(vinyl acetate-co-vinyl alcohol) blends. An infrared study. Macromolecules 26, 7256-7262 (1993).

55. Cesteros, L. C., Isasi, J. R. \& Katime, I. Study of the miscibility of poly(vinyl pyridines) with poly(vinyl acetate), poly(vinyl alcohol) and their copolymers. J. Polym. Sci. Pol. Phys. 32, 223-230 (1994).

\section{Acknowledgements}

X.L. is grateful to the European Union (EU) for a Marie Curie Postdoctoral Fellowship C.E.B. thanks the Bristol Chemical Synthesis Centre for Doctoral Training funded by the Engineering and Physical Sciences Research Council (EPSRC) for a PhD studentship. M.A.W. thanks the Natural Sciences and Engineering Research Council of Canada for financial support. I.M. thanks the EU for a European Research Council Advanced Investigator Grant. We also thank the Wolfson Bioimaging Facility at the University of Bristol for the use of the confocal microscopy facilities.

\section{Author contributions}

X.L., Y.G. and I.M. conceived the project and wrote the manuscript with input from M.A.W. X.L., Y.G. and C.E.B. carried out the experiments. I.M. supervised the project with input from M.A.W.

\section{Additional information}

Supplementary information accompanies this paper at http://www.nature.com/ naturecommunications

Competing financial interests: The authors declare no competing financial interests.

Reprints and permission information is available online at http://npg.nature.com/ reprintsandpermissions/

How to cite this article: $\mathrm{Li}, \mathrm{X}$. et al. Non-covalent synthesis of supermicelles with complex architectures using spatially confined hydrogen-bonding interactions. Nat. Commun. 6:8127 doi: 10.1038/ncomms9127 (2015).

This work is licensed under a Creative Commons Attribution 4.0 International License. The images or other third party material in this article are included in the article's Creative Commons license, unless indicated otherwise in the credit line; if the material is not included under the Creative Commons license, users will need to obtain permission from the license holder to reproduce the material. To view a copy of this license, visit http://creativecommons.org/licenses/by/4.0/ 